\title{
The Analysis \& Prevention of Safety Hazards in NFL Complex
}

\author{
Prem Baboo \\ National fertilizers ltd. India
}

\begin{abstract}
The success of any industries lies its efficient working which in turn depends not only on equally and quantity of the service or product but also much on safe working. NFL is totally committed to conduct all its activities in harmony with society and nature without compromising on the health and safety of the employees as well as the people living around the complex. A full-fledged safety and environment protection department has been set up in the unit to achieve fulfillment of its statutory obligations concerning prevention of personal injuries, maintaining safe working conditions and protection of environment. For effective implementation of Safety, Health \& Environment (SHE) policy, Each and every employee shall observe the safe system of work and follow proper safety work permit system while carrying out maintenance job inside the factory. This paper provides the detailed analysis of these hazards: In which plant sections and during which project phase do these safety hazards occur, which safety hazards occur most frequent and which hazards has the highest risk factor and troubleshooting case study and further improvement to learn these incidents. The most critical safety hazards and recommends its prevention and mitigation measures. New surprising conclusion is that most safety hazards may lead to a sudden release of toxic ammonia. Suggestions how to safely behave in a urea plant and how to identify a maximum number of safety hazards, risk factor in primary reformer ,ammonia receiver and compressors house. With this objective comprehensive information has been described in this article ammonia/chlorine and others chemicals about its proprietaries toxic effect, fire hazard, safety appliances, and safety incorporated. Detail analysis of NFL Panipat incident. Study of high temperature Hydrogen Attack, which in an Ammonia plant typically occurs in areas such as secondary reformers, waste heat boilers/exchangers, high temperature shift converters, and methanator and synthesis loop equipment's. Check list through the weep holes if leaks occur from lining and from the lined parts of high and medium pressure equipment. In case of leaks of liquid or gas the plant shall be shut down immediately and the damage repaired.
\end{abstract}

\section{INTRODUCTION}

National Fertilizers Ltd, (NFL) operates a fertilizer complex at Vijaipur, Distt. Guna (Madhya Pradesh), India consisting of two units Vijaipur-I and Vijaipur-II, plants were commissioned in December 1987 and March 1997 respectively. Ammonia Plants are based on M/s. HTAS's Steam Reforming of Natural Gas and Urea plants are based on M/S. Saipem's Ammonia Stripping technology. NFL, a Schedule 'A' \& a Mini Ratna (Category-I) Company. The Vijaipur unit, which is an ISO 9001:2000 \& 14001 certified, comprises of two streams. The Vijaipur have two ammonia plant M/S. Haldor Topsoe Technology, Denmark capacity 1750 \& 1864 TPD for Line-I \& line-II respectively and four urea plant of M/S. Saipem ammonia stripping process, Italy.
The capacity of Urea-I urea - II is 3030 \& 3231 TPD respectively. The raw material used includes natural gas, water and power. Three Numbers Captive power plant of capacity 17 X $3 \mathrm{MW}$ are used in this complex. The Complex manufactured about 2100000MT urea per anuum while manufacturing fertilizers, Hazardous explosive gases handled or stored day by -in and day out. An explosion due to an explosive hydrogen/ammonia/air mixture in the M.P. vent in combination with a loss of mechanical integrity of the line. Deterioration of the mechanical integrity of the inerts washing unit exit and subsequent failure under operating conditions. There are two tanks- one of 10,000 MT (single walled) and other one of 5,000 MT capacities (double walled). Both are having common flare stack. The concrete foundations of these tanks are checked periodically. The controls are operated by DCS system and display is received on the computer screen.

The major explosive or toxic gases handled at Vijaipur unit are
1. Natural gas
2. Hydrogen
3. Carbon Mono Oxide
4. Ammonium Carbamate
5. Ammonia
6. Chlorine
7. Sulphuric Acid
8. Sodium Hydroxide

The first four gases are only handled within pipeline or processing equipment's but the last four are stored within the complex in bulk quantity. Major areas of failures are reforming and synthesis loop. Ammonia is a toxic substance. Ammonia forms flammable and explosive mixture with air in the range of 16 to $25 \%$ concentration by volume. Its auto ignition temperature is $651^{\circ} \mathrm{C}$.The presence of oil in the ammonia or mixture of ammonia with other combustible materials will increase the fire hazards. In a urea plant, relative large amounts of ammonia are present under elevated temperature and pressure. Traditionally, ammonia containing gases from such emergency relief systems (safety valves or rupture disks) from urea plants has been directly discharged to the atmosphere via blow down. Large release of ammonia due to accident and vessel failure etc. Some safety hazards refer to two or more incidents indicating that its frequency may be higher than other safety hazards. This is valuable input when performing safety assessment exercises. The safety manual provides an overview of the safety hazards involved in a urea plant. But not only the hazards are identified and listed, also each 
hazard is quantified by means of a risk factor and prevention and mitigation measures are suggested plus reference is made to companies who are able to provide support for implementing these measures. Risk safety manual are a valuable information source for any HAZOP and safety study of a urea plant.

Following topic covered in this article.

1. Risk Assessment for ammonia/Urea plant a detail learning.

2. Hazard Evaluation and prevention in ammonia/Urea Plant.

3. Problem, Failure and Safety Analysis of ammonia/urea Plant.

4. Analysis of safety hazard in ammonia/urea plant.

5. Risk analysis of Ammonia/Urea Plant.

6. Learning from safety failure in Ammonia/Urea Plants

7. Lesson learnt process safety in ammonia/urea plant.

8 learning from safety mistake in ammonia/urea plants.

Risk Analysis: Provides a relative measure of the likelihood and severity of various possible hazardous events by critically examining the plant process and design.

Work Safety Analysis: The technique discerns whether the plant layout and operating procedures in practice have any inherent infirmities.

Safety Audit: Takes a careful look at plant operating conditions, work practices and work environments to detect unsafe conditions. The NFL conducts external safety audit every year.

Together, above three broad tools attempt to minimize the chances of accidents occurring. Yet, there always exists, no matter how remote, probability of occurrence of a major accident. If the accident involves highly hazardous chemicals in sufficiently large quantities, the consequences may be serious to the plant, to surrounding areas and the populations residing therein.

Brief Process description of ammonia plant and probability of incidents.

To design \& operation reliable of Ammonia plant it is necessary to take into account many aspects, such as the process safe shut down, mechanical design of all parts, equipment's, instrumentation, process control, and the plant as approachable layout. The Ammonia process is characterized mainly by gaseous fluids, mixtures of hydrogen, methane, steam, air, carbon mono and dioxides and ammonia. Gaseous mixtures are generally not corrosive; therefore, carbon and low alloy steels are extensively used in ammonia plants, but if they are at high temperature and/or high pressure they can become highly aggressive and require special design and material selection to assure reliable operations, the most challenging sections are the reforming and the synthesis sections.

The ammonia plant is quite complicated gas plant that foresees different chemical reactions and operations working on range of operative condition that $-2{ }^{\circ} \mathrm{C}$. Operation can contribute to Ammonia and condition $-2^{\circ} \mathrm{C}$ up to elevated temperature $1000^{\circ} \mathrm{C}$ as well as from low pressure $1 \mathrm{bar}$ to high pressure $250 \mathrm{bar}$. The know-how to manage all the wide range of operative condition and fluids to be handled is of the most importance. The know-how to manage all the wide range of operative condition and fluids to be handled is of the most importance. The Ammonia process is characterized mainly by gaseous fluids, dangerous mixtures of hydrogen, methane, steam, air, carbon mono and dioxides and ammonia. Gaseous mixtures are generally not corrosive but explosive in nature, therefore carbon and low alloy steels are extensively used in ammonia plants, but if they are at high temperature and/or high pressure they can become highly aggressive and require special design and material selection to assure reliable operations. The most challenging sections are the reforming and the synthesis sections. In the reforming section the high Temperatures, in some part above $900^{\circ} \mathrm{C}$ are a challenge in itself, but the presence of hydrogen, carbon mono and dioxide and steam in the gas can lead to phenomena such as metal dusting, which can have catastrophic consequences.

The National Fertilizers Ltd. Vijaipur line-I \& 2 have following sections.

Desulphurization section:

The desulphurization takes place in two steps:

Hydrogenation, where organic sulphur is converted into hydrogen sulphide $\left(\mathrm{H}_{2} \mathrm{~S}\right)$ over the hydrogenation catalyst in the HDS reactors.

$\mathrm{RSH}+\mathrm{H}_{2} \leftrightarrows \mathrm{RH}+\mathrm{H}_{2} \mathrm{SWhere}$, " $\mathrm{R}$ " is a radical of hydrocarbon.

$\mathrm{H}_{2} \mathrm{~S}$ absorption, which takes place in the series, in $\mathrm{ZnO}$ absorbers.

$\mathrm{ZnO}+\mathrm{H}_{2} \mathrm{~S} \leftrightarrows \mathrm{ZnS}+\mathrm{H}_{2} \mathrm{~S}$

$\mathrm{ZnO}+\mathrm{COS} \leftrightarrows \mathrm{ZnS}+\mathrm{CO}_{2}$

After the desulphurization, the content of sulphur will be less than $0.05 \mathrm{ppm}$ (by volume).

Reforming section:

In the reforming section, catalytic reforming of the hydrocarbon mixture with steam and addition of air convert the de sulphurized gas into raw ammonia synthesis gas.

Reactions:

The steam reforming process can be described by the following reactions:

$\mathrm{C}_{\mathrm{n}} \mathrm{H}_{2 \mathrm{n}+2}+2 \mathrm{H}_{2} \mathrm{O} \leftrightarrows \mathrm{C}_{\mathrm{n}-1} \mathrm{H}_{2 \mathrm{n}}+3 \mathrm{H}_{2}-$ Heat.

$\mathrm{CH}_{4}+2 \mathrm{H}_{2} \mathrm{O} \leftrightarrows \mathrm{CO}_{2}+4 \mathrm{H}_{2}-$ Heat.

$\mathrm{CO}_{2}+\mathrm{H}_{2} \leftrightarrows \mathrm{CO}+\mathrm{H}_{2} \mathrm{O}-$ Heat

The reaction takes place in two steps when, natural gas is the feedstock,

1) Primary reforming

2) Secondary reforming

And in three steps, when natural gas mixed with naphtha is the feedstock,

1) Adiabatic pre-reformer

2) Primary reformer

3) Secondary reformer

When the ammonia plant is fed on the natural gas only the adiabatic pre-reformer,

R 3206 is bypassed.

Adiabatic pre-reformer, R3206 
The hydrocarbon feed from the desulphurization section is mixed with the process steam and preheated in a coil, E 3201 , installed in the flue gas waste heat section of the primary reformer. All the higher hydrocarbons are virtually decomposed into methane by steam reforming by means of the pre reformer catalyst.

Primary reformer, H 3201

In the case of natural gas used as feedstock the first step of the steam reforming process takes place in the primary reformer, $\mathrm{H}$ 3201. In the naphtha case, the outlet gas feeds H320 from the adiabatic pre-reformer, R 3206. The mixture of steam and hydrocarbon is passed downwards through vertical tubes containing catalyst. The primary reformer is a fired heater where the sensible heat and heat of reaction are transferred by radiation from a number of wall burners to the catalyst tubes. It has a total of 288 reformer tubes and 576 burners installed in two radiant sections. The outlet gases leaving the primary reformer, contains approx. about $10-11 \%$ of methane (on dry basis).

\section{Secondary Reformer, R 3203}

In secondary reformer, $\mathrm{R} 3203$, the process gas is mixed with the air. The partial combustion takes place in the upper part of R 3203 and causes a considerable increase in temperature. From the combustion chamber the gas passes down through a catalyst bed, where the last part of reforming takes place with the simultaneous cooling of the gas. The gas leaving the secondary reformer contains about 13 mole $\% \mathrm{CO}, 7.3 \% \mathrm{CO}_{2}$ and 0.30 mole $\%$ methane.

Gas Purification section:

The gas purification section comprises of three main process steps:

(i) $\mathrm{CO}-$ conversion (Shift section)

(ii) $\quad \mathrm{CO}_{2}$ removal (the GV section)

(iii) Methanation

(i) $\mathrm{CO}-$ conversion (Shift section)

In this section, the carbon monoxide is converted into carbon dioxide and hydrogen by means of the shift reaction, which takes place in the two CO converters,

R 3204, high temperature converter

R 3205, low temperature converter

(ii) Carbon dioxide removal ( $\mathrm{GV}$ section)

Basically, the $\mathrm{CO}_{2}$ removal section comprises,

1. One absorber, $\mathrm{F} 3303$, where the $\mathrm{CO}_{2}$ content in the process gas is absorbed in a liquid phase at high pressure.

2. Two tower, F 3301 and F 3302, regeneration unit, where the pressure is low and thereby, due to equilibrium, the $\mathrm{CO}_{2}$ again will be transferred into the gas phase.

Reactions:

The $\mathrm{CO}_{2}$ absorption occurs according to the following reaction mechanism:

$$
\begin{aligned}
& \mathrm{CO}_{2}+\mathrm{H}_{2} \mathrm{O} \leftrightarrows \mathrm{HCO}_{3}^{-}+\mathrm{H}^{+} \\
& \mathrm{CO}_{3}^{--}+\mathrm{H}_{2} \mathrm{O} \leftrightarrows \mathrm{HCO}_{3}^{-}+\mathrm{OH}^{-} \\
& \mathrm{CO}_{3}^{--}+\mathrm{CO}_{2}+\mathrm{H}_{2} \mathrm{O} \leftrightarrows 2 \mathrm{HCO}_{3}^{-}
\end{aligned}
$$

The activator action resulting in an increased rate is caused by the quick transfer of gaseous $\mathrm{CO}_{2}$ into the liquid phase by means of the glycine carbamate formation according to the reaction:

$\mathrm{H}_{2} \mathrm{NCH}_{2} \mathrm{COO}^{-}+\mathrm{CO}_{2} \leftrightarrows \mathrm{OOCNHCH}_{2} \mathrm{COO}^{-}+\mathrm{H}^{+}$

The activator effect is much higher than the one relating to carbamate concentration. At high temperature and in the presence of the $\mathrm{OH}$, the carbamate is hydrolyzed and the activator is restored according to the following reaction:

\section{$\mathrm{OOCNHCH}_{2} \mathrm{COO}^{-}+\mathrm{H}_{2} \mathrm{O} \leftrightarrows \mathrm{H}_{2} \mathrm{NCH}_{2} \mathrm{COO}^{-}+\mathrm{HCO}_{3}^{-}$}

The sum of 4 and 5 gives 1 . as reaction 4 and 5 takes place continuously, it means that the glycine acts as a $\mathrm{CO}_{2}$ carrier. Reaction 5 is the hydrolysis of glycine carbamate. The reaction is catalyzed by a small amount of DEA in the solution.

(iii) Methanation

The final part of the gas purification is the Methanation, where residual carbon oxides are converted into methane, which acts as an inert gas in the ammonia synthesis loop. As previously mentioned, the carbon dioxide and $\mathrm{CO}$ are severe poison to the ammonia synthesis catalyst. The Methanation takes place in the Methanation, $\mathrm{R}$ 3311. The purified gas contains $\mathrm{N}_{2}, \mathrm{H}_{2}$ and approx. 1 mole\% of inerts as $\mathrm{Ar}, \mathrm{CH}_{4}$ and $\mathrm{H}_{2} \mathrm{O}$. The ratio of $\mathrm{H}_{2}$ and $\mathrm{N}_{2}$ is $3: 1$.

\section{Reactions:}

The reactions involved in the Methanation are reversed of the reforming:

$$
\begin{aligned}
& \mathrm{CO}+3 \mathrm{H}_{2} \leftrightarrows \mathrm{CH}_{4}+\mathrm{H}_{2} \mathrm{O}+\text { Heat } \\
& \mathrm{CO}_{2}+4 \mathrm{H}_{2} \leftrightarrows \mathrm{CH}_{4}+2 \mathrm{H}_{2} \mathrm{O}+\text { Heat }
\end{aligned}
$$

Ammonia synthesis section:

The ammonia synthesis takes place in the ammonia synthesis converter, R 3501, where only $30 \%$ of the nitrogen and hydrogen are converted into ammonia.

Reaction:

$2 \mathrm{H}_{2}+\mathrm{N}_{2} \leftrightarrows 2 \mathrm{NH}_{3}+$ Heat

The reaction is reversible and only a part of hydrogen and nitrogen is converted into ammonia by passing through the catalyst bed. To get the max. Overall yield of the synthesis gas, the unconverted part is recycled to the converter after separation of the liquid ammonia. The heat liberated by the reaction (about $750 \mathrm{kcal} / \mathrm{kg}$ produced ammonia) is utilized for high-pressure steam production and preheat of highpressure boiler feed water. 


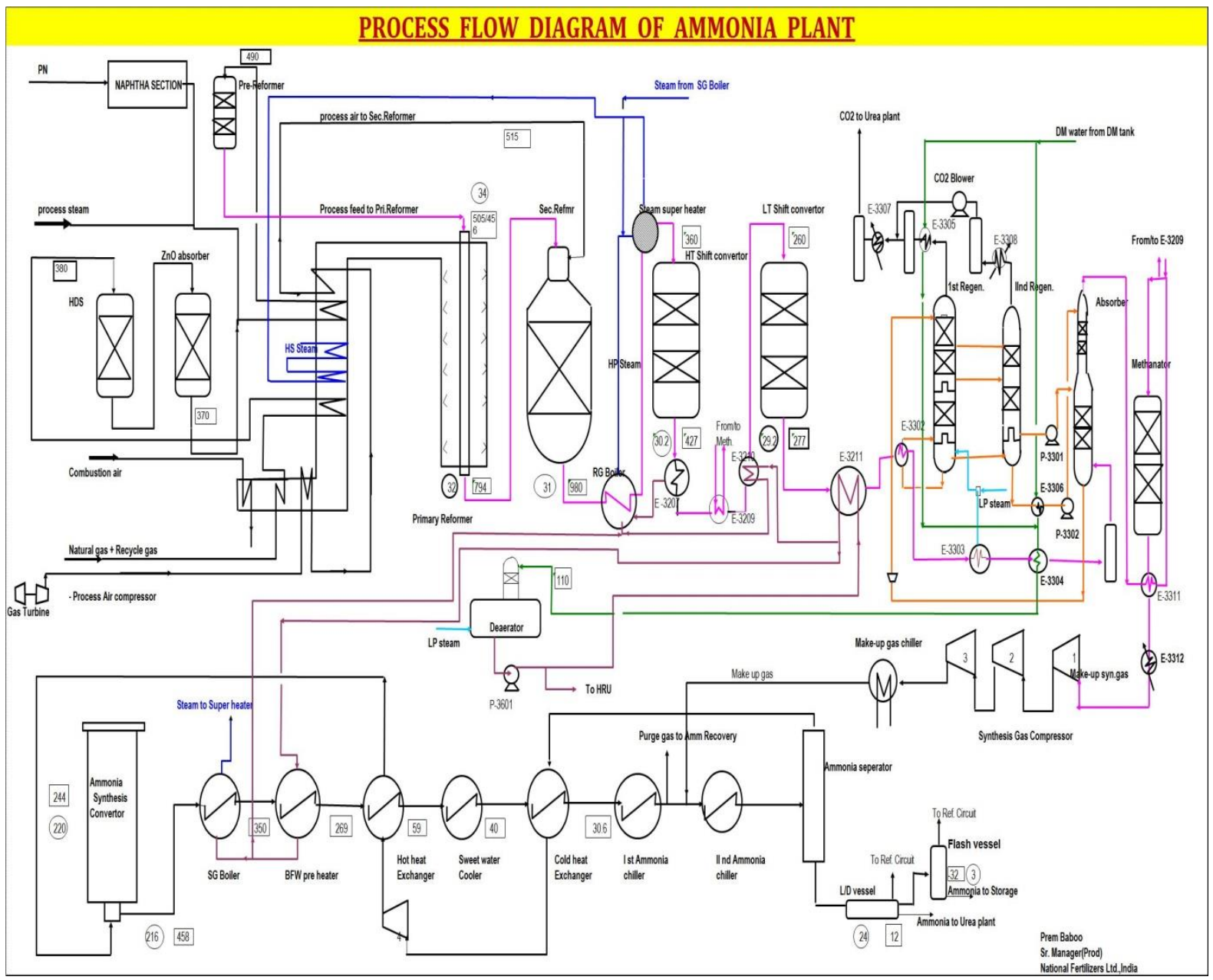

The probability of accidents in Reformer section

The hydrogen attack is used to indicate several phenomena linked to the damages caused by hydrogen. The most considerable ones for ammonia plants are:

High Temperature Hydrogen Attack, which in an Ammonia plant typically occurs in areas such as secondary reformers, waste heat boilers/exchangers; high temperature shift converters, methanator and synthesis loop the conditions under which attack can occurs. Hydrogen assisted cracking, which has also been detected in Ammonia plants vessels, in particular where the component had not been adequately post weld stress relieved during fabrication. For this reason Hydrogen assisted cracking can occur service temperatures well below the relevant Nelson curve. Generally, it occurs in low alloy with a chrome level above $2 \%$, typically utilized in the hottest part of the synthesis section.

Fire observed on dated 14/05/2018

Fire observed on reformer common steam isolation valve due to Hydrogen. No causality was occurred but one people face was burnt, however some waste material likes cotton waste \& wooden material burnt. Immediately action was taken. The reason was common steam isolation valve was closed before closing hydrogen isolation valve due to communication gap between CCR Panel and field.

One more problem occurred
Fig-1

HTS Converter upper layer of top bed temperature was increased to $600^{\circ} \mathrm{C}$ due to miss operation however no catalyst damaged was found.

Reasons for problems faced during startup

HTS Converter upper layer of top bed temperature was increased to $600^{\circ}$ Process air compressor was running and process air block valve 32 USV-108 might have passing and process air ingress through process air path to secondary reformer subsequently to HTS Converter while nitrogen purging. It may be the reason for HTS converter temperature increase. Water ingress from GV circulation pump's seal or passing of quench valve might have resulted in dilution of GV Solution.

Remedial measures:

1. Process air block valve 32 USV-108 will be attended in next shutdown.

2. Hourly readings of all catalyst bed temperature will be noted down during shut down.

3. GV column levels to be monitored and levels to be note down regularly. Seal water to pumps to be minimized during shutdown period.

4. Shift wise intermittent lab analysis of GV solution during startup and shutdown period.

Forced shutdown owing to breakdown of bearing of ID Fan of Primary Reformer resulted in production loss of 35.67 hrs. Shutdown of 24 hours prolonged to 36 hours and plant had to be operated on low load for about 34 hours. 


\section{Common precaution for Reformer}

In ammonia plant hydrogen and natural gas are burnable material. The natural gas supplied by outside agency while hydrogen produced after primary reformer and secondary reformer. A slight mistake can lead to an accident. Proper sequence in process operation must be there. In Table No 1 shows the maximum possibility their resolved and fixing of responsibility.

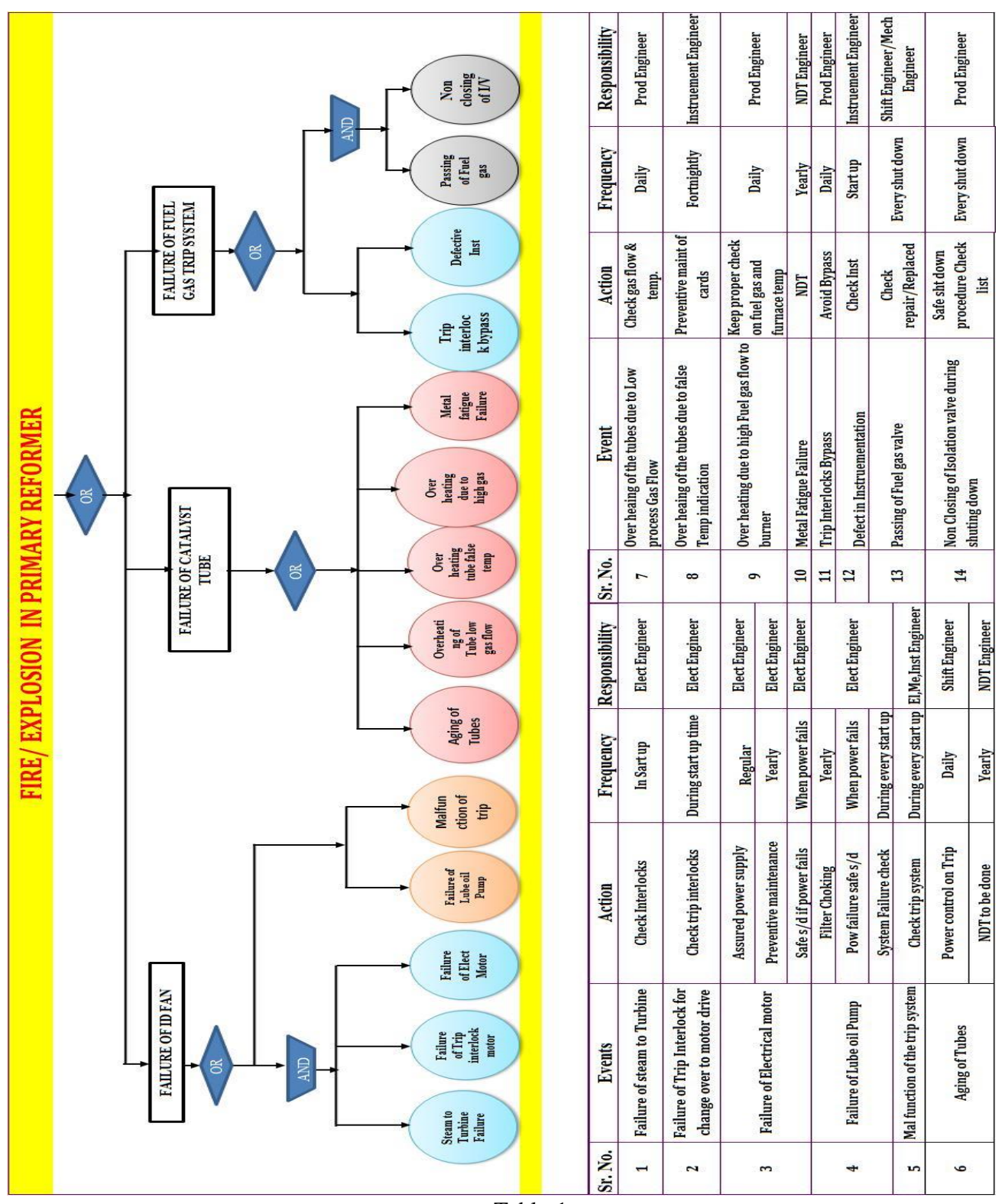

Table-1

Emergency plan for NFL Vijaipur.

Following advantages for emergency plan

1. To avoid loss, Injury, minimize Impact of damage.

2. It is an important element of EHS management.

3. To Identify and eliminate potential emergencies.

4. To identify organizational weaknesses.

5. To Address Business risks of inadequate response.

6. Promotion of EHS.

7. Demonstration of commitment.

8. To meet Legal requirements.

Major incident occurred in NFL Panipat detail analysis-

An incident of the ammonia release occurred on $26^{\text {th }}$ August 1992 in National Fertilizers Ltd. Panipat (Haryana) India.
On the morning of August 26 on end of the ammonia some pressure drop was observed in the discharge end of the ammonia pump provided before the urea drop was observed in the discharge end of the ammonia pump provided before the urea rector. When search was made it was observed that the safety valve provided at the discharge end of the pump was passing. On the instruction of the shift in charge the stand by pump was started and the pump C was isolated. The pump was depressurized and flushed. While the safety valve was being replaced by the maintenance operator with his helper under the foreman maintenance, the operator of the urea plant and the shift in charge of the urea plant, the isolation valve had failed and the liquefied urea start releasing at the pressure of $26 \mathrm{~kg} / \mathrm{cm} 2$. The routine job of 
replacing the defective safety valve of the ammonia Feed pump at 15 years old urea plant and began to replacing the valve when the unthinkable happened. Vaporizing within the seconds to form suffocating clouds of the deadly gas. This hit and choked to death eleven people and injured the ten even as their colleagues sprung into the action diffuse the gas with water spray. The ammonia had released into the atmosphere from the open port of the safety valve in the form of the spray. Some person was completely drenched with the liquefied ammonia. The atmosphere was suddenly filled with dense cloud of ammonia involving the persons within it. The rescue and relief operation were soon started but by the time the victims taken to the factory hospital 10 persons had died and 11 others sustained serious injuries.

On the day of accident also valve had been hammered to ensure total stoppage of the flow. The maintenance team had brought another safety valve. The task involved removing of the existing valve and fitting another valve at its place in order to bring the defective valve to the workshop for repairing and testing. The condition found after the incident than the existing had been removed isolation valve had failed and started releasing the ammonia gas through the open port of the safety valve. Immediately after that the area got covered with fogy fumes. The information of the event reached to all quickly and rescuers with self-contained breathing apparatus entered the cloud for searching the trapped persons. Emergency siren was raised, though no one acted as per the responsibility distribution in the onsite emergency plan.
As soon as the information of the ammonia leakage spread in the plant, the about 25 breathing sets were brought from safety department to the site of incident. About 21 breathing sets were used by the persons involved in the rescue operation. The fire services of the plant were involved in spraying of water in the leakage zone. Keeping the wind direction in view the areas towards wind ward direction were being evaluated in the plant. The urea plant was shut down by use of emergency push button which closes the activities with shortest possible period.

The nearest fire call point was broken to inform the fire department about the event. The first fire tender reached within 3-4 minutes after starting the event. After that the order fire tender also joined.

There was need to stopped the alternate ammonia pump in order to stop the pump. The switch was in the area where the cloud was dense. No one could approach the valve. Then electric department was asked to switch off the power from the main supply to the plant.

The person who were rescued reach the factory hospital within 8-10 minutes. After the event has controlled the cause of the valve failure was checked, it was found that the valve collar of the glove valve had broken allowing the spindle of the valve in upward direction.

The person engaged in the rescue and control operations were also affected by the ammonia exposure. They were first taken to the company hospital. But next day such people were admitted in the hospital

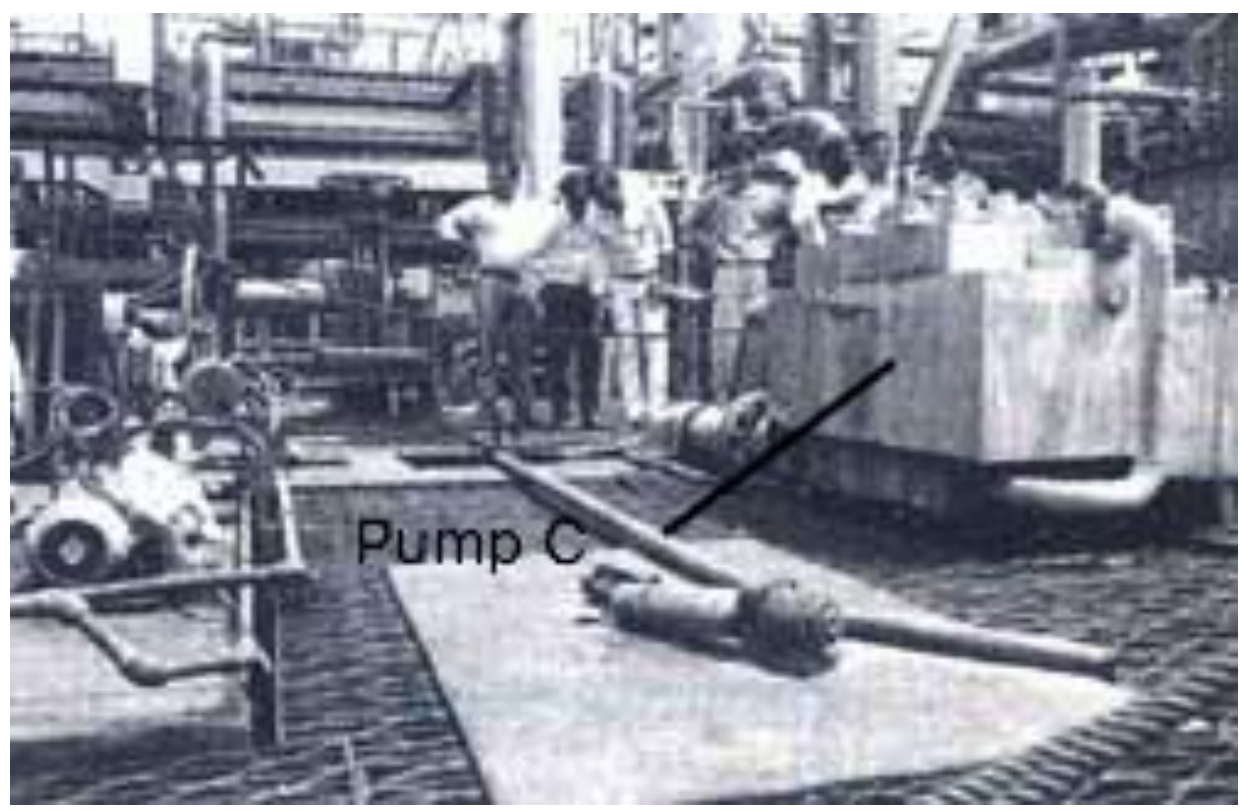

Fig-2

\section{Cause of valve Failure}

The subsequent accident investigations indicated that the cause of the incident was lifting of valve spindle due to rupture of the collar of the valve. The care full looking on the broken pieces of the valve indicated that the about half of the collar had developed some time back as it has turned black, whereas the remaining part of the broken surface was shining white. This indicated that the crack had taken place some time back due to repeated hammering of the lever.
Lesson learnt from the event.

The causes of the frequent failure of safety valves should be identified and necessary actions should be taken. The safety valve and the isolation valve before the safety valves should be marked with the identified numbers. The isolation valve before the safety valves should be locked open. The safety work permit should be signed by the safety officer duly countersigned by the issuing authority. The permit signing authority should ensure that the precaution indicated in the 
permit. The isolation of the machine having toxic or flammable substances should be dissolved in water by suitable process and should be lagoon to release slowly in the atmosphere the designer instructions regarding type of valve to be used should be strictly followed. In case the deviations from the original designed are required the manufacturer of the machines should be consulted.

Every proposal for change the process should be critically analyzed by HAZOP study. Globe valve should not be tested for any crack in the collar by dye penetration test or other equivalent technique. Condition of the thread should also be checked to not allow any slip. The emergency plan should be made a practical instrument for mitigate the effect of the events.
The escape route from pump platform should be increased to promote the escape of the person in case of such events. Provision of waste spray in ammonia compressor area should be considered. All the SCBAs should be equipped with low pressure alarms and working in continuous positive pressure mode. The SCBA working only on demand mode should be marked and levels that these will not use when there is risk of live or health.

Quick modification done in other units of NFL.

After the Panipat incident, the motorized valve provided in other units of NFL so that in case of incident this ammonia can be protected to vented out as fig No. 3 .

Fig-2

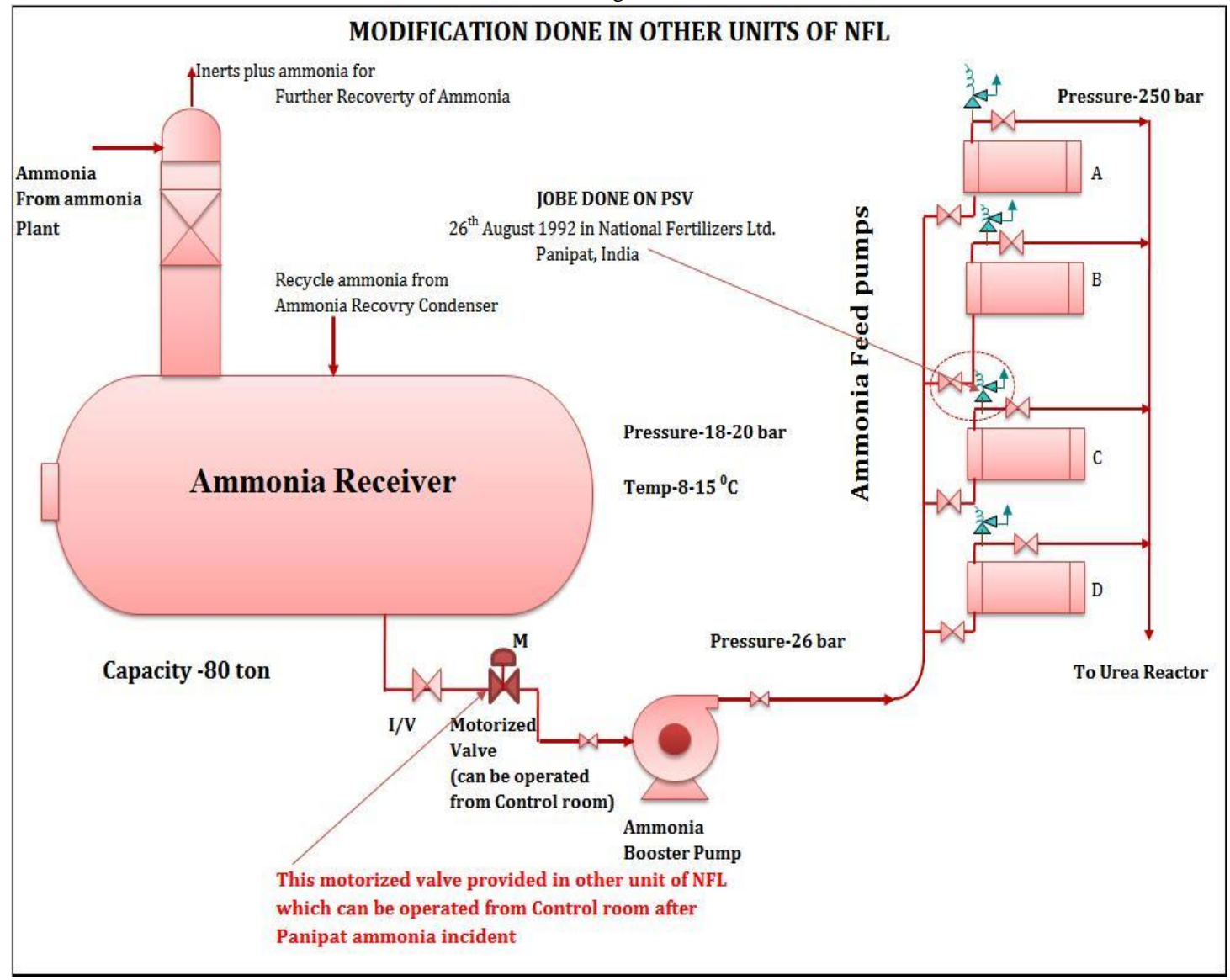

Fig-3

The possibility of failure of ammonia receiver in urea plant is summarized in table No. 2, also what action should be taken? And responsibility of the person. 


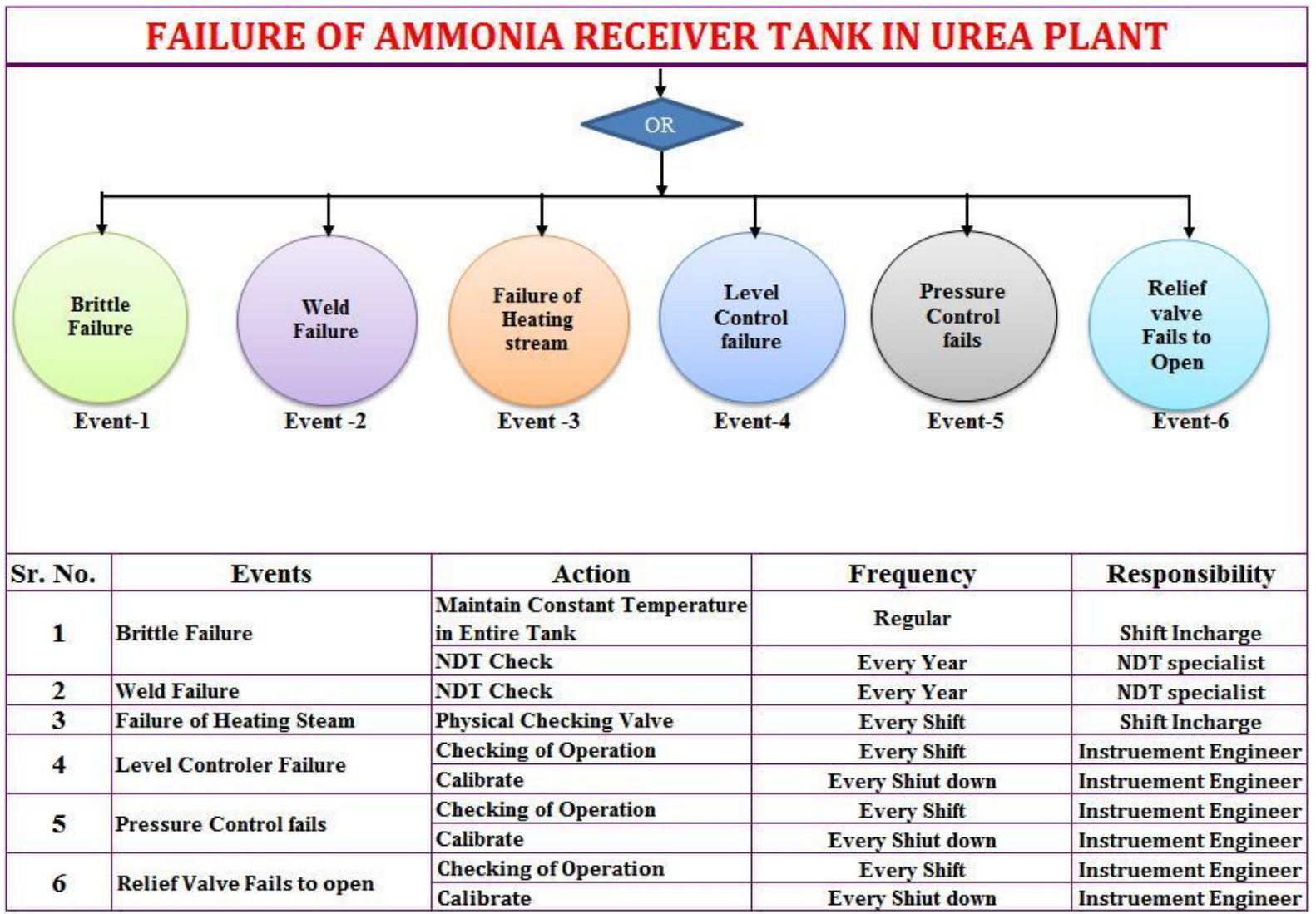

Table-2

Incident on dated 18/09/2018 Failure of one plunger packing of Ammonia reciprocating Pump

In NFL Vijaipur unit, one reciprocating plunger packing was failure on dated 18/09/2018. Huge amount dense ammonia like cloud observed. The ammonia pump has five number plungers and discharge pressure is about 250 bar. The plant was running on full load at about $11.30 \mathrm{hrs}$. Ammonia leakage was started due failure of $5^{\text {th }}$ number plunger. Immediate stopped the plant and closed the booster pump motorized suction valve from control room immediately control the situation this lesson have learnt from Panipat incident. This motorized valve provided after Panipat incident. The manual valve cannot be operated in field because huge dense ammonia was there. In high pressure pump house area a water curtains also provided with control valve which can be operated from control room. An ammonia sensor also provided in each pump house and at 50 ppm of ammonia the alarm appears on central control room. Immediately water curtains control valve open to control ammonia.

Risk in Urea Reactor.

Urea Reactors form the centre of any urea plant. High pressures and temperatures, the corrosive

Circumstances and the health risks of ammonia in case of a leak put high demands to the integrity of such a vessel. As it is well knowing the modern urea processes are recycle type of process, therefore a temporary or sudden inefficiency of the synthesis loop, or more in detail of the urea reactor, would have a significant impact on the overall urea plant performances and under certain conditions may even lead to a plant shutdown. One of the challenges in operating a urea plant is to combat the corrosive process environment in the High-pressure vessel in synthesis section. To protect the pressure vessel a corrosion resistant barrier is applied. The reliability and safety depends on the choice of the stainless steel, the fabrication methods, quality of welding and last but not least inspections and maintenance during the total life cycle. Weep hole monitoring. Any weakness in the protective barrier, either introduced during fabrication or during operations will increase the risk of (catastrophic) failure.

These designs typical for most urea reactors currently in operation. The reactor liner is continuously monitored for leakages. Instrument air is introduced in one of the weep holes and the air coming out from other weep holes are monitored for any leakage in the liner. Weekly physical monitoring of weep holes is also done. 48 points for each reactor have been provided. The HP stripper, carbamate separators and condensers are also provided with weep holes and leakages are checked regularly in every shift. In Vijaipur weep hole monitoring system with conductivity meter probe installed. The hazard risk history register is a collection of possible hazards that can occur in such a urea reactor and includes the related mitigation measures: one learnt why instead of only what. A fact that proves to be unexpectedly enlightening is that one can conclude from that $65 \%$ of the identified hazards can be mitigated by operating a proper leak detection system. 


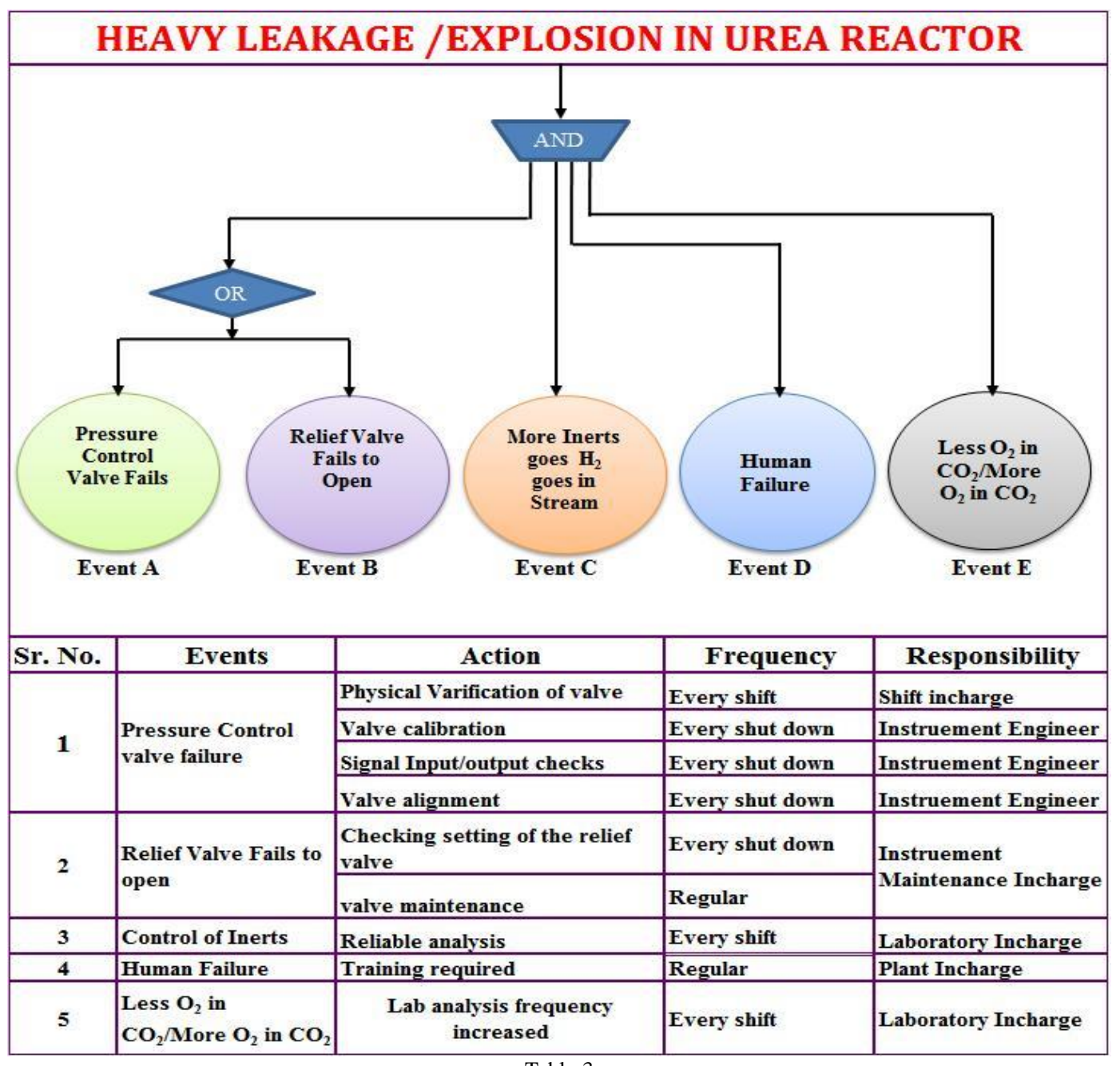

Table-3

Stripper Tube old plug Failure on dated 19/01/2018

A critical leak incident that occurred in one of the most critical piece of equipment (stripper) in Urea plant resulted to emergency shutdown and losses in production and how the situation can be analyzed to prevent re- occurrence of similar incidents in chemical Industry. On dated 19/01/2018 at $05.30 \mathrm{hrs}$. Suddenly 31 stream urea stripper got heavy leakage and carbamate came out through pressure safety valve in shell side of heat exchanger (stripper). A rupture in old plug of the tube of a high pressure caused leakage of high pressure urea solution and ammonium carbamate to the atmosphere which results to emergency shutdown and losses in production for three days. Leakage was so big that Shell became pressurized up to PSV setting value i.e. 26.0 bar. Immediately shut down was taken to control the situation. If shut down not taken then everything could have happened. The intent of this topic is to highlight the issues faced in identification of Urea Stripper leakage during plant operation and rectification of the problems.

Risk in compressors by Carbamate backflow
Among the hazardous arising from the use mineral oil as lubricant or coolant in compressor are fire and explosion. At the turbine is sometime oil leakages are there this oil leakages is very dangerous to fire. The risk in $\mathrm{CO} 2$ tabulated in table No- In CO2 compressor all stages discharge lines MOC are used Carbon steel while all suction lines are stainless steel. The Final discharge line also is made up of carbon steel; sometime carbamate backflow occurred in this line and sometimes there is a continuous back-pressure caused by a liquid head because the closing action of control valve is slow and failure of NRV. The corrosion rate in CS material is very high about $1000 \mathrm{~mm} /$ year means the $25-\mathrm{mm}$ thickness line totally corroded and carbamate can come out in only 8-10 days this can lead incidents.

Remedies

The backflow of carbamate can be avoided by simple arrangement as shown in the fig- 4 , means the control valves must be closed with machine trip interlocks. Two NRV with flashed vessel (delivery drum) are to be provided so that the pressure can be reduced in backflow. The two number NRV upstream and downstream of this Flashed vessel must be there. 

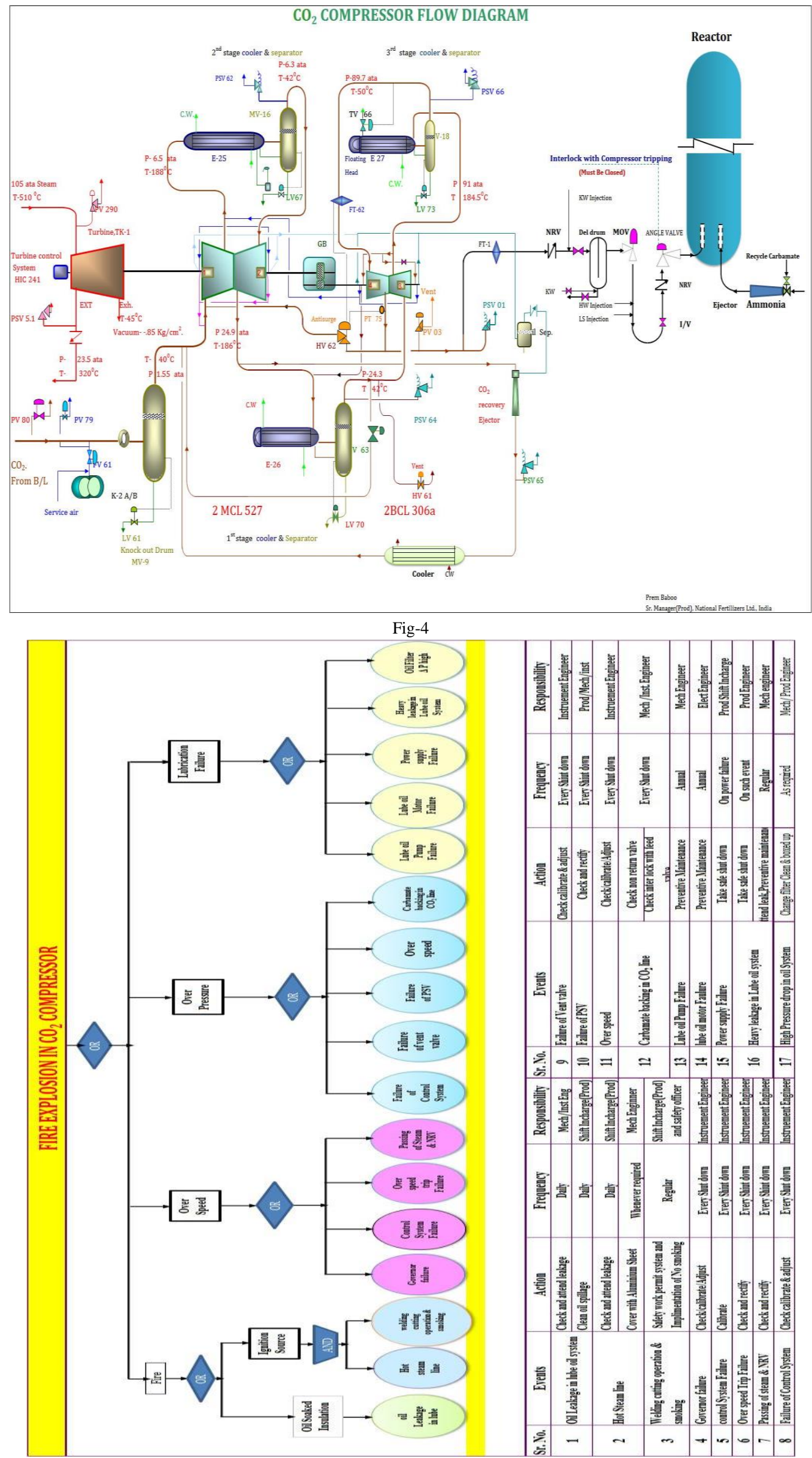

Table- 4 


\section{CONCLUSION}

Ammonia is one among the largest volume inorganic chemicals in the chemical process industries and used mainly for production of fertilizers using steam. Reforming of natural gas.in urea plant there is possibility of explosion in presence of Hydrogen and oxygen. Safety meeting is the right time to discuss about health and safety related matters in the workplace. Safety meeting can be held regularly or incidentally as a response on occurrence of a specific health and safety problem or after an incident or accident happens. Ideally, safety meeting focuses on just one specific topic. But, what kind of topics do we have to discuss? Here are some topics that you can use in the safety meeting:

Large release of ammonia due to accidents and vessel failures etc. Major areas of concerns/ failures are reforming and synthesis loop causing fires and shutdowns. Above study reveals that all the stages/aspects of a plant like design, risk assessment, material of construction, Corrosion, vibration backflow of carbamate solution in $\mathrm{CO}_{2}$ compressor, fabrication process, inspection (including material supplied by vendors), maintaining operating parameters during normal operation, adherence to the guidelines during operation as well as maintenance, periodic inspection of equipment's and machineries can prevent failures and shutdowns in the plant resulting in improved performance. Further, periodic training, motivation and feedback from operating personnel are most important and should be followed in right spirit to improve the performance of plant.

Legends

1. SCBA-Self-Contained Breathing Apparatus.

2. HAZOP-Hazards and operability.

3. DCS-Distributed Control system

\section{REFERENCES}

(1) Risk Register of a Urea Reactor Learn why... instead of only what...by Mr. mark Brouwer.

(2) Urea stripper Tube leakage, International journal of Engineering Research \& Technology by Prem Baboo 